\title{
Nematofauna fitopatogênica de sementes comerciais de forrageiras tropicais
}

\author{
Carlos Eduardo Marchi(1), Celso Dornelas Fernandes ${ }^{(1)}$, Caroline Tchatcha Borges ${ }^{(2)}$, Jaime Maia dos Santos ${ }^{(3)}$, \\ Vanessa de Fátima Jerba ${ }^{(1)}$, Renata Aline Trentin ${ }^{(2)}$ e Luciana Roberta de Araújo Guimarães ${ }^{(2)}$
}

\begin{abstract}
(1)Embrapa Gado de Corte, Caixa Postal 154, CEP 79002-970 Campo Grande, MS. E-mail: cemarchi@cnpgc.embrapa.br, celsof@cnpgc.embrapa.br, vjerba@cnpgc.embrapa.br (2)Universidade para o Desenvolvimento do Estado e da Região do Pantanal, Caixa Postal 2153, CEP 79003-010 Campo Grande, MS. E-mail: carolt_borges@hotmail.com, renata_at@ibest.com.br, lulubioguimaraes@yahoo.com.br (3)Universidade Estadual Paulista, Fac. de Ciências Agrárias e Veterinárias, Via de Acesso Prof. Paulo Donato Castellane, s/no, CEP 14880-900 Jaboticabal, SP. E-mail: jmsantos@fcav.unesp.br
\end{abstract}

\begin{abstract}
Resumo - O objetivo deste trabalho foi identificar e quantificar a nematofauna fitopatogênica de sementes de forrageiras, destinadas aos mercados interno e externo. Examinaram-se sementes de Brachiaria brizantha (cvs. Marandu e Xaraés), B. decumbens cv. Basilisk, Panicum maximum (cvs. Massai, Mombaça e Tanzânia) e Stylosanthes capitata e S. macrocephala, componentes da cultivar Estilosantes Campo Grande. As extrações foram realizadas por flotação centrífuga, em solução de sacarose com caulim. Nas gramíneas, encontraram-se os gêneros Aphelenchoides e Ditylenchus. O maior número de espécimes de Aphelenchoides spp. foi observado nas sementes de 'Marandu', e, em seguida, nas sementes de 'Xaraés', 'Basilisk' e 'Tanzânia'. Quanto à densidade populacional de Ditylenchus spp., os maiores valores foram observados nas sementes de 'Marandu', 'Xaraés' e 'Basilisk'. Os resultados sugerem que pelo menos duas espécies de Aphelenchoides e Ditylenchus estão associadas às sementes de gramíneas forrageiras, destinadas ao mercado interno. Fitonematóides não são detectados em sementes de 'Estilosantes Campo Grande', tampouco nas cultivares Marandu, Mombaça e Tanzânia, destinadas à exportação.
\end{abstract}

Termos para indexação: Aphelenchoides, Ditylenchus, fitonematóides, pastagem, produção de sementes.

\section{Phytopathogenic nematofauna of commercial seeds of tropical forages}

\begin{abstract}
The objective of this work was to identify and quantify the phytopathogenic nematofauna of forage seeds destined for internal and external markets. Seeds of Brachiaria brizantha (cvs. Marandu and Xaraés), B. decumbens cv. Basilisk, Panicum maximum (cvs. Massai, Mombaça and Tanzania), and Stylosanthes capitata and S. macrocephala, components of cv. Estilosantes Campo Grande, were examined. The extractions were made by centrifugal flotation in solution of sucrose with kaolin. Aphelenchoides and Ditylenchus genera were detected in forage grasses. The highest number of Aphelenchoides spp. specimens was observed in seeds of cv. Marandu, followed by seeds of cvs. Xaraés, Basilisk, and Tanzania. Regarding Ditylenchus spp. population density, higher values were detected in seeds of cvs. Marandu, Xaraés, and Basilisk. The results suggest that two or more species of Aphelenchoides and Ditylenchus are associated to forage grass seeds destined for Brazilian market. Phytopathogenic nematodes are not detected in Estilosantes Campo Grande seeds, neither in seeds of cvs. Marandu, Mombaça and Tanzania destined for exportation.
\end{abstract}

Index terms: Aphelenchoides, Ditylenchus, plant nematodes, pasture, seed production.

\section{Introdução}

A produção de sementes de forrageiras tropicais no Brasil vem crescendo acentuadamente nos últimos anos, como consequiência da demanda dos mercados interno e externo. Atualmente, o país é considerado o maior produtor, consumidor e exportador de sementes de forrageiras (Andrade et al., 2004). Grande parte das sementes produzidas tem sido comercializada internamente, e o restante é exportado, principalmente, para países da América do Sul e Central (Fernandes et al., 2005).

Apesar de economicamente expressivo, o sistema de produção de sementes de forrageiras encontra-se ameaçado pela presença de patógenos. Em virtude da ausência de padrões de sanidade para o mercado 
brasileiro, as sementes têm atuado como mecanismo eficiente de introdução e dispersão de muitos patógenos e pragas, que podem afetar desde a fase de estabelecimento do estande até a colheita do produto.

Entre os patógenos associados às sementes de forrageiras tropicais, destacam-se os fitonematóides (Favoreto, 2004). Embora não existam pesquisas que demonstrem os danos causados às pastagens, acreditase que os fitonematóides podem ter impacto significativo sobre a produção de matéria seca e persistência das forrageiras no campo (Favoreto, 2004). Bernard et al. (1998) mencionaram que os fitonematóides não somente reduzem a produção como também a qualidade da forragem.

Além dos danos diretos, os fitonematóides constituem grande entrave para as exportações de sementes forrageiras. Grandes importadores de sementes de Brachiaria sp. e Panicum sp. impõem restrições fitossanitárias ao produto brasileiro.

Estudos sobre a associação de fitonematóides e sementes de forrageiras tropicais são incipientes no Brasil. Sabe-se que Aphelenchoides spp., sobretudo $A$. besseyi, são encontradas com freqüência em sementes de Brachiaria spp., P. maximum, Setaria italica, Cyperus spp. e Digitaria sanguinalis, inclusive em sementes de germoplasma importadas (Tenente et al., 1994, 2000; Garcia \& Tenente, 2001; Bueno et al., 2002; Favoreto et al., 2006b). Da mesma forma, Ditylenchus spp. têm sido relatadas em gramíneas forrageiras (Favoreto et al., 2006b). Com relação às leguminosas forrageiras, são escassas as informações da nematofauna fitopatogênica nas sementes produzidas no país.

Estratégias adequadas para erradicar os fitonematóides das sementes de forrageiras tropicais têm sido estudadas (Garcia et al., 2000; Garcia \& Tenente, 2001; Tenente, 2003; Favoreto et al., 2006a). Contudo, para o estabelecimento dessas estratégias, é crucial conhecer a nematoufauna das sementes das principais cultivares forrageiras. O objetivo deste trabalho foi identificar e quantificar os gêneros de fitonematóides associados às sementes de forrageiras tropicais comercializadas em Mato Grosso do Sul, bem como às sementes destinadas ao mercado externo.

\section{Material e Métodos}

Foram analisadas sementes de $B$. brizantha (cvs. Marandu e Xaraés), B. decumbens cv. Basilisk,
P. maximum (cvs. Mombaça, Tanzânia e Massai), e Stylosanthes capitata e S. macrocephala, componentes de 'Estilosantes Campo Grande', que foram produzidas em Paraíso, MS, na safra 2004/2005. As amostras de sementes foram fornecidas por empresa produtora e comercializadora em Mato Grosso do Sul, coletadas de lotes destinados ao comércio interno.

Foram, também, avaliadas sementes de $B$. brizantha cv. Marandu e de P. maximum (cvs. Mombaça e Tanzânia) de alta qualidade, destinadas ao mercado externo. Tais amostras foram cedidas por empresas distintas da anterior, com sede em Mato Grosso do Sul. As sementes das cultivares de P. maximum e da cv. Marandu foram produzidas em Camapuã, MS, e Rio Verde, GO, respectivamente, durante a safra 2004/2005. Sementes comercializadas no mercado interno constituíram os tratamentos-controle.

Para a extração de nematóides, empregou-se o método de Coolen \& D'Herde (1972), em delineamento experimental inteiramente casualizado, com quatro repetições por lote de semente. Amostras de $10 \mathrm{~g}$ de sementes foram trituradas com aproximadamente $200 \mathrm{~mL}$ de água em liquidificador, por 20 segundos. Em seguida, a suspensão com restos vegetais foi passada em peneira de 28 mesh, sobre outra de malha de 400 mesh, sob água corrente. A partir da peneira de malha 400 mesh, e com o auxílio de pisseta, recolheu-se a suspensão de nematóides e tecido vegetal em béquer de $100 \mathrm{~mL}$. Essa suspensão, cerca de $50 \mathrm{~mL}$, foi transferida para um tubo de centrífuga, onde se adicionou $1 \mathrm{~cm}^{3}$ de caolim. Após homogeneização, a suspensão foi submetida à centrifugação de $1.750 \mathrm{rpm}$ por 4 minutos. Em seguida, descartou-se o sobrenadante, e completou-se o volume do tubo com solução de sacarose a $45 \%$. A mistura foi homogeneizada, e novamente procedeu-se à centrifugação a $1.750 \mathrm{rpm}$ por 1 minuto. O sobrenadante obtido após tal procedimento foi vertido em peneira de 400 mesh e, com o auxílio de pisseta, recolheu-se a suspensão de nematóides em béquer de $100 \mathrm{~mL}$. Essa suspensão, com aproximadamente $20 \mathrm{~mL}$, foi transferida para tubo de ensaio, que permaneceu em geladeira por 24 horas, para sedimentação e agrupamento dos nematóides.

Com o uso de seringa acoplada à mangueira plástica, retirou-se o excesso de água da suspensão de nematóides, tendo-se deixado apenas $4 \mathrm{~mL}$. Esse volume foi homogeneizado, e a alíquota de $1 \mathrm{~mL}$ foi depositada em câmara de Peter, para a identificação e quantificação dos nematóides em microscópio de luz. Com base nas 
características morfológicas dos espécimes observados, os fitonematóides presentes foram identificados e quantificados.

Após a quantificação, a suspensão de nematóides foi transferida para placa de Petri de $5 \mathrm{~cm}$ de diâmetro e, com auxílio de microscópio estereoscópico e estilete com pêlo de porco, procedeu-se à coleta de alguns espécimes, que foram depositados em lâminas para análise em microscópio de luz. Os detalhes mais relevantes foram registrados por meio de sistema de captura de imagem.

As análises de variância e testes de comparação de médias, da densidade populacional de fitonematóides, foram realizadas com o programa SAS (SAS Institute, 2003).

\section{Resultados e Discussão}

Fitonematóides e nematóides de vida-livre foram observados em associação com as sementes de forrageiras tropicais produzidas em Paraíso, MS, cujos lotes eram destinados à comercialização interna. Os resultados das extrações de nematóides estão descritos na Tabela 1. Nas gramíneas, foram encontrados espécimes machos e fêmeas de Aphelenchoides spp. e Ditylenchus spp. Tais gêneros têm sido detectados em sementes de forrageiras tropicais, sobretudo Aphelenchoides. Tenente (2003) observou sementes de P. maximum, provenientes de áreas de produção de Campo Grande, MS, naturalmente infectadas por A. besseyi. Aphelenchoides spp., notadamente A. besseyi, e Ditylenchus spp. também foram relatadas em sementes de B. brizantha, por Favoreto et al. (2006a, 2006b). Segundo esses autores, Aphelenchoides spp. infectam predominantemente as sementes de B. brizantha, ao contrário de Ditylenchus spp., que são mais encontradas nas impurezas junto às sementes.

O maior número de Aphelenchoides spp. foi encontrado nas sementes do capim-marandu.
As sementes dessa cultivar também apresentaram a maior densidade populacional de Ditylenchus spp., sem diferir, no entanto, das densidades nas cultivares Basilisk e Xaraés (Tabela 1).

Observou-se associação mais freqüente de Aphelenchoides spp. às sementes das braquiárias. Exceção feita à cultivar Tanzânia, sementes de $P$. maximum apresentaram densidade populacional desse fitonematóide menor do que a observada nas sementes de braquiárias (Tabela 1). Esta tendência também foi evidenciada para Ditylenchus spp. Os menores números de espécimes desse gênero foram observados nas sementes de $P$. maximum.

Nas amostras de sementes de gramíneas forrageiras, foram detectados espécimes do gênero Aphelenchoides que exibiam região labial arredondada, lisa e ligeiramente mais larga que o primeiro anel do corpo, estilete de $15 \mu \mathrm{m}$, cauda conoidal com três a quatro mucros (Figura 1 A, B, D e F). Essas características morfológicas sugeriram tratar-se de A. besseyi (Favoreto, 2004). Foram, também, encontrados espécimes com caracteres distintos de $A$. besseyi, como a presença de cauda mucronada, com apenas uma expansão pontiaguda (Figura $1 \mathrm{C}$ e E). Espécimes de Aphelenchoides spp. semelhantes, com apenas um mucro na cauda, foram observados por Favoreto (2004) em sementes de $B$. brizantha. Tais fitonematóides não foram identificados até o nível de espécie.

Os espécimes de Ditylenchus spp. também apresentaram características morfológicas aparentemente distintas, o que indica, possivelmente, que mais de uma espécie de Ditylenchus encontrava-se associada a sementes das gramíneas forrageiras. Entre os caracteres distintos, destacou-se o formato da cauda e número de estrias no campo lateral. Foram observados indivíduos cuja cauda apresentou terminação subaguda ou arredondada (Figura 2 A, B, E e F), bem como espécimes que apresentavam campo lateral, com quatro ou mais de quatro estrias (Figura 3). Espécimes de Ditylenchus spp. com mais de quatro estrias no campo lateral,

Tabela 1. Número de espécimes de Aphelenchoides spp. e Ditylenchus spp. associados às sementes de Brachiaria sp., Panicum maximum e Stylosanthes spp., produzidas em Paraíso, MS, na safra 2004/2005, e destinadas ao mercado interno ${ }^{(1)}$.

\begin{tabular}{lcc}
\hline Forrageira & Aphelenchoides spp. \\
\hline Brachiaria brizantha cv. Marandu & $156 \mathrm{a}$ & Ditylenchus spp. \\
B. brizantha cv. Xaraés & $91 \mathrm{~b}$ & $120 \mathrm{a}$ \\
B. decumbens cv. Basilisk & $73 \mathrm{~b}$ & $109 \mathrm{a}$ \\
Panicum maximum cv. Massai & $52 \mathrm{c}$ & $111 \mathrm{a}$ \\
$P$. maximum cv. Mombaça & $57 \mathrm{c}$ & $57 \mathrm{c}$ \\
$P$. maximum cv. Tanzânia & $85 \mathrm{~b}$ & $85 \mathrm{~b}$ \\
Stylosanthes capitata + S. macrocephala (Estilosantes Campo Grande) & $88 \mathrm{~b}$ \\
\hline
\end{tabular}

${ }^{(1)}$ Número de espécimes por $10 \mathrm{~g}$ de sementes; médias seguidas por letras iguais, na coluna, não diferem entre si pelo teste de agrupamento de Scott-Knott, a $5 \%$ de probabilidade. 
especificamente seis estrias, também foram observados em amostras de sementes de B. brizantha, por Favoreto (2004). Com base na morfologia desses espécimes, esse autor concluiu tratar-se de D. myceliophagus, até então não relatado em $B$. brizantha. Nas mesmas amostras de sementes de $B$. brizantha, o referido autor ainda detectou outras espécies de Ditylenchus, porém não as identificou.

Com relação à leguminosa Estilosantes Campo Grande, não foram detectados fitonematóides em suas sementes

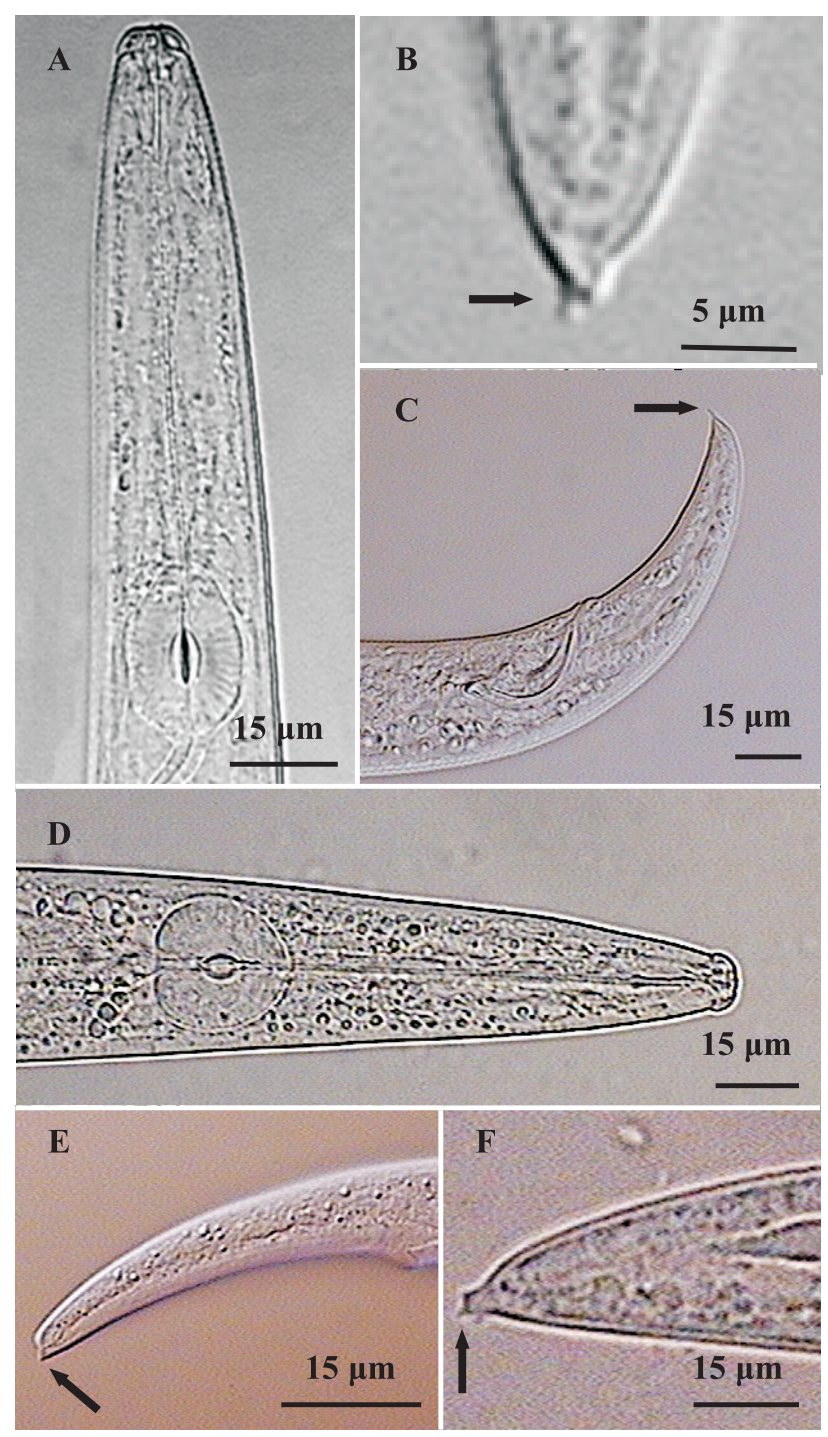

Figura 1. Aphelenchoides spp. detectado em sementes de gramíneas forrageiras, produzidas em Paraíso, MS, na safra 2004/2005. Panicum maximum cv. Massai: região anterior (A), cauda com mais de um mucro (B) e cauda com um mucro (C). Brachiaria brizantha cv. Xaraés: região anterior (D), cauda com um (E) ou mais mucros (F). Setas: presença de mucros.
(Tabela 1). O fato de a colheita ser realizada a partir das inflorescências contribuiu para a produção de sementes livres de fitonematóides, principalmente no caso de Ditylenchus spp., que são mais associadas às impurezas junto às sementes (Favoreto et al., 2006a). No caso de B. brizantha, esses autores constataram que o beneficiamento das sementes resulta em redução da população de Ditylenchus spp.
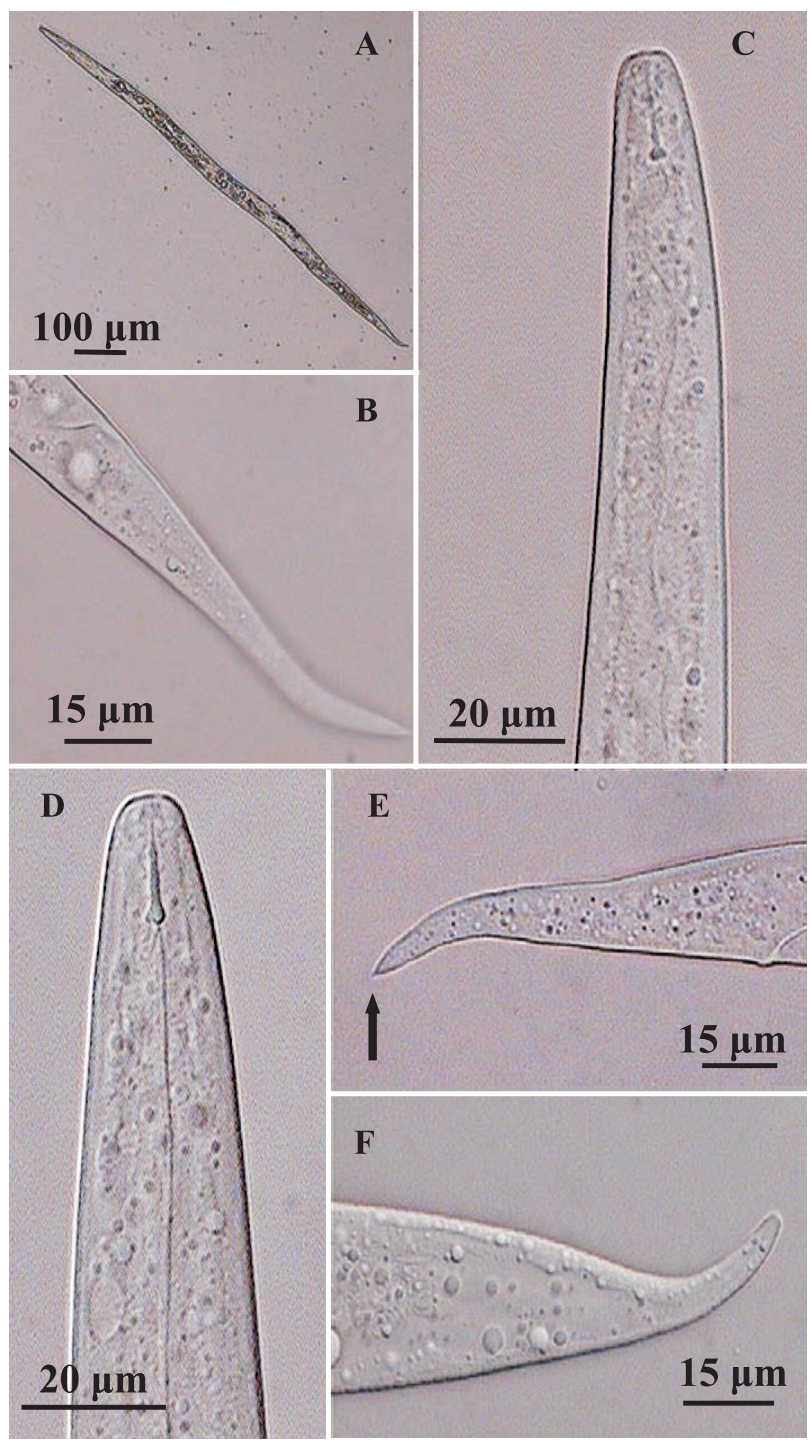

Figura 2. Ditylenchus spp. detectado em sementes de gramíneas forrageiras, produzidas em Paraíso, MS, na safra 2004/2005. Panicum maximum cv. Tanzânia: aspecto do nematóide (A), cauda (B) e região anterior (C). Brachiaria brizantha cv. Xaraés: região anterior (D), cauda com um mucro (E) e não mucronada (F). Seta: presença de mucro. 
Além disso, é possível que a escarificação mecânica realizada nas sementes da leguminosa, antes da comercialização para a superação da dormência física, tenha apresentado efeito negativo sobre a nematofauna fitopatogênica. Para Aphelenchoides spp., tal fato foi evidenciado. Espécimes desse fitonematóide foram detectados em sementes não escarificadas, embora em baixa frequiência (aproximadamente cinco espécimes por $10 \mathrm{~g}$ de sementes). Esses resultados indicaram a possibilidade de Aphelenchoides spp. acompanhar o ponto de crescimento das plantas, semelhantemente ao observado em arroz (Bedendo \& Prabhu, 2005).

Os resultados das análises de sementes de alta qualidade, destinadas ao comércio externo, estão sumarizados na Tabela 2. Não foram detectados nematóides vivos em nenhuma das amostras. Alguns espécimes inativos foram observados, contudo, em razão
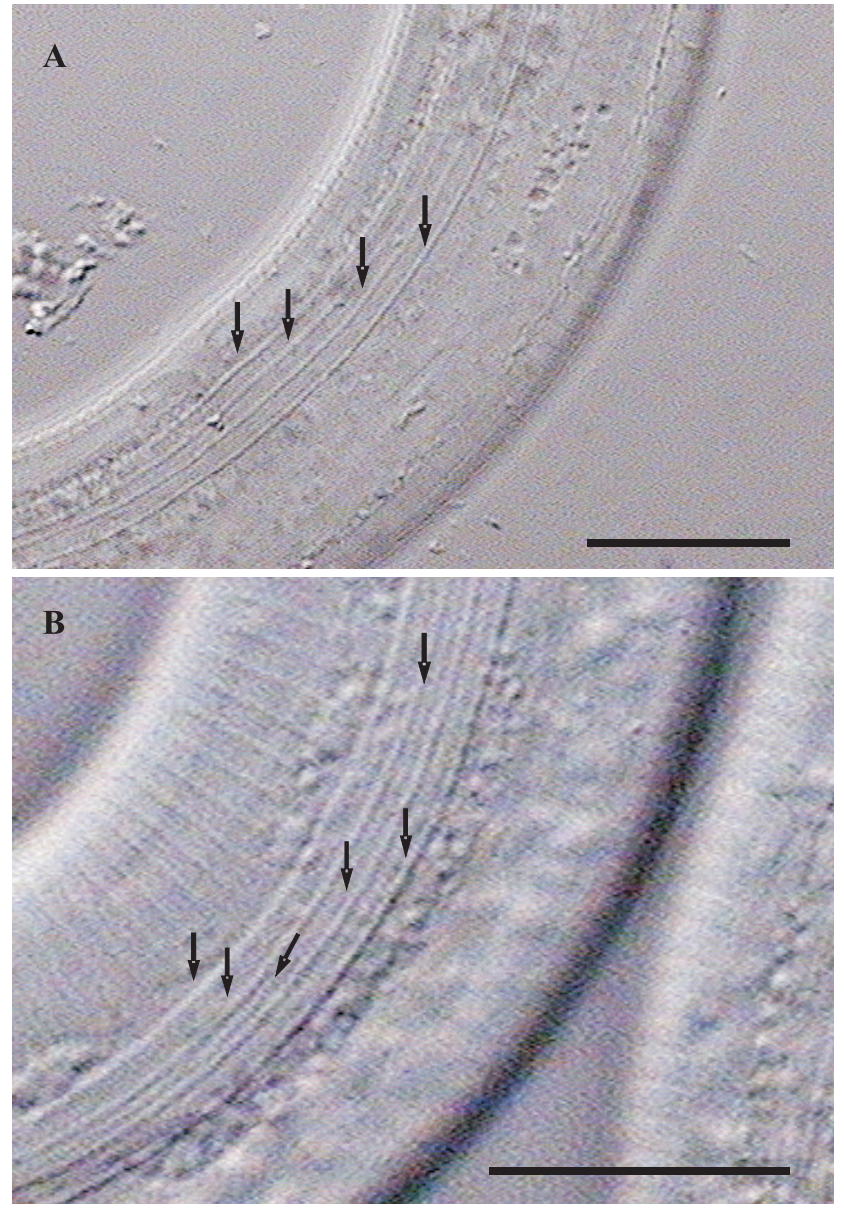

Figura 3. Campo lateral de Ditylenchus spp. detectado em sementes de Brachiaria brizantha cv. Xaraés, produzidas em Paraíso, MS, na safra 2004/2005. Setas: presença de quatro (A) ou mais estrias (B). Barra: $20 \mu \mathrm{m}$.
Tabela 2. Número de espécimes de Aphelenchoides spp. e Ditylenchus spp. associados às sementes de Brachiaria brizantha cv. Marandu e Panicum maximum, produzidas em Rio Verde, GO, e Camapuã, MS, respectivamente, na safra 2004/ 2005, e destinadas aos mercados interno (MI) e externo $(\mathrm{ME})^{(1)}$.

\begin{tabular}{lcc}
\hline Forrageira & $\begin{array}{c}\text { Aphelenchoides } \\
\text { spp. }\end{array}$ & $\begin{array}{c}\text { Ditylenchus } \\
\text { spp. }\end{array}$ \\
\hline Brachiaria brizantha cv. Marandu (MI) & $80 \mathrm{a}$ & $86 \mathrm{a}$ \\
Panicum maximum cv. Tanzânia (MI) & $72 \mathrm{a}$ & $75 \mathrm{a}$ \\
P. maximum cv. Mombaça (MI) & $63 \mathrm{a}$ & $75 \mathrm{a}$ \\
B. brizantha cv. Marandu (ME) & $0 \mathrm{~b}$ & $0 \mathrm{~b}$ \\
P. maximum cv. Tanzânia - Lote A (ME) & $0 \mathrm{~b}$ & $0 \mathrm{~b}$ \\
P. maximum cv. Tanzânia - Lote B (ME) & $0 \mathrm{~b}$ & $0 \mathrm{~b}$ \\
P. maximum cv. Mombaça (ME) & $0 \mathrm{~b}$ & $0 \mathrm{~b}$ \\
\hline
\end{tabular}

(1)Número de espécimes por $10 \mathrm{~g}$ de sementes; médias seguidas por letras iguais, na coluna, não diferem entre si pelo teste de agrupamento de Scott-Knott, a 5\% de probabilidade.

de alterações morfológicas, possivelmente decorrentes de tratamentos das sementes com ácido sulfúrico ou formaldeído, não foram identificados. Nas amostras de sementes comercializadas no país, foram detectados espécimes de Aphelenchoides spp. e Ditylenchus spp.

$\mathrm{O}$ fato de as sementes de forrageira tipo exportação apresentarem maior qualidade física, como menor presença de terra, torrões, gravetos e palhas, por si só contribuiu para a melhor qualidade sanitária dessas sementes. Isto é particularmente importante para a erradicação de Ditylenchus spp., que estão mais freqüentemente associadas ao exterior das sementes de forrageiras (Favoreto et al., 2006a). Ademais, as exigências de tratamentos das sementes com ácido sulfúrico ou formaldeído, impostas por países importadores, aparentemente podem contribuir para a produção de sementes livres de fitonematóides.

\section{Conclusões}

1. Fitonematóides estão associados às sementes de forrageiras comercializadas em Mato Grosso do Sul, e são freqüentemente detectados os gêneros Aphelenchoides e Ditylenchus.

2. Pelo menos duas espécies de Aphelenchoides e Ditylenchus estão presentes nos lotes de sementes comerciais de forrageiras tropicais destinadas ao mercado interno.

3. Sementes de 'Estilosantes Campo Grande', comercializadas em Mato Grosso do Sul, não apresentam fitonematóides veiculados.

4. Sementes de B. brizantha cv. Marandu e P. maximum cvs. Mombaça e Tanzânia, destinadas ao mercado externo, não apresentam fitonematóides veiculados. 


\section{Agradecimentos}

À Fundect-MS e ao CNPq, pelo apoio financeiro à pesquisa; à Embrapa Gado de Corte, pela oportunidade de realizar o trabalho.

\section{Referências}

ANDRADE, R.P. de; VILLAS BOAS, H.; SILVEIRA, G.C.; PAIVA, L. A parceria Embrapa-Unipasto e seu impacto na pesquisa e desenvolvimento de pastagens tropicais do Brasil. Brasília: Abrasem, 2004. Disponível em: <http://www.abrasem.com.br/ materia_tecnica/2004 /0008_parceria_embrapa_unipastos.htm $>$. Acesso em: 5 maio 2005.

BEDENDO, I.P.; PRABHU, A.S. Doenças do arroz. In: KIMATI, K.; AMORIM, L.; REZENDE, J.A.M.; BERGAMIN FILHO, A.; CAMARGO, L.E.A. (Ed.). Manual de fitopatologia. São Paulo: Ceres, 2005. v.2, p.79-90.

BERNARD, E.C.; GWINM, K.D.; GRIFFIN, G.D. Forage grasses. In: BARKER, K.R.; PETERSON, G.A.; WINDHAM, G.L.; BARTELS, J.M.; HATFIELD, J.M.; BAENZIGER, P.S.; BIGHAM, J.M. (Ed.). Plant and nematode interactions. Madison: American Society of Agronomy, 1998. p.427-454.

BUENO, E.R.V.; PRATES, M.; TENENTE, R.C.V. Avaliação de métodos tradicionais de extração de nematóides aplicados à sementes de Panicum maximum infestadas por Aphelenchoides besseyi. Nematologia Brasileira, v.26, p.213-217, 2002.

COOLEN, W.A.; D'HERDE, C.J. A method for the quantitative extraction of nematodes from plant tissue. Ghent: Nematology and Entomology Research Station, 1972. 77p.

FAVORETO, L. Estudo de nematóides em sementes de gramíneas forrageiras. 2004. 43p. Dissertação (Mestrado) Universidade Estadual Paulista, Jaboticabal.
FAVORETO, L.; SANTOS, J.M. dos; BARBOSA, J.C.; CALZAVARA, S.A. Fitonematóides extraídos dos resíduos das fases do beneficiamento e de sementes de Brachiaria brizantha. Nematologia Brasileira, v.30, p.203-209, 2006a.

FAVORETO, L.; SANTOS, J.M. dos; CALZAVARA, S.A.; BARBOSA, J.C. Avaliação comparativa de métodos para extração de nematóides de sementes de gramíneas forrageiras. Nematologia Brasileira, v.30, p.71-74, 2006b.

FERNANDES, C.D.; MARCHI, C.E.; JERBA, V.F.; BORGES, M. de F. Patógenos associados às sementes de forrageiras tropicais e estratégias de controle. In: ZAMBOLIM, L. (Ed.). Sementes, qualidade fitossanitária. Viçosa: UFV, 2005. p.183-213.

GARCIA, J.W.; TENENTE, R.C.V. Controle químico de Aphelenchoides besseyi Chistie em sementes de Panicum maximum. Nematologia Brasileira, v.25, p.95-98, 2001.

GARCIA, J.W.; TENENTE, R.C.V.; MENDES, M.A.S. Thermal treatment applied to Panicum maximum seeds for eradication of Aphelenchoides besseyi and plant pathogenic fungi. Nematologia Brasileira, v.24, p.41-47, 2000.

SAS INSTITUTE (Cary, Estados Unidos). SAS/STAT software: changes and enhancements through release 9.1. Cary, 2003. 5136p.

TENENTE, R.C.V. Tratamento físico contra nematóides de sementes. Brasília: Embrapa Recursos Genéticos e Biotecnologia, 2003. 8p. (Circular técnica, 21).

TENENTE, R.C.V.; MANSO, E.C.; GONZAGA, V. Nematóides detectados em germoplasma vegetal importado e sua erradicação nos anos de 1995-1998. Nematologia Brasileira, v.24, p.79-81, 2000.

TENENTE, R.C.V.; MANSO, E.S.B.G.C.; MENDES, M.A.S.; MARQUES, A.S. dos A. Seed health testing for nematode detection and treatment of plant germplasm in Brazil. Seed Science and Technology, v.22, p.415-420, 1994.

Recebido em 27 de outubro de 2006 e aprovado em 9 de abril de 2007 